\title{
Expression Profile of Pro-Inflammatory Cytokines in Head-Kidney Leucocytes of Rohu Following Stimulation with Poly I:C
}

Pujarini Dash and PK Sahoo*

Fish Health Management Division, ICAR-Central Institute of Freshwater Aquaculture, Kausalyaganga, Bhubaneswar, India

Received: January 30, 2017; Accepted: March 14, 2017; Published: May 09, 2017

*Corresponding author: Dr. PK Sahoo, Ph.D, Principal Scientist \& ICAR National Fellow, Fish Health Management Division, ICAR-CIFA,

Kausalyaganga, Bhubaneswar, India-751002, Tel: +91-674-246546; Fax: +91-674-2465407; E-mail: Pksahoo1@Hotmail.Com

\begin{abstract}
IL (interleukin)-6, TNF (tumor necrosis factor)- $\alpha$, IL-1 $\beta$ and IL-8 are pro-inflammatory cytokines which augment host inflammatory reactions in response to multiple stresses or infections. In this study, we analyzed expression profile of these cytokines in head kidney leucocytes (HKL) isolated from healthy rohu (Labeo rohita) juveniles in response to poly I:C $(50 \mu \mathrm{g} / \mathrm{ml})$, a synthetic dsRNA virus analog stimulation. RNA was isolated from stimulated HKLs at $0,1,3,6,12$, 24 , and 72 and 96 h post-stimulation (hps) and the expression profile of IL-6, TNF- $\alpha$, IL- $1 \beta$ and IL- 8 was studied using qPCR. IL- 6 expression was found to be significantly up-regulated at $72 \mathrm{hps}$ whereas higher level of TNF- $\alpha$ was evident at $96 \mathrm{hps}$. With regard to IL-8 and IL-1 $\beta$, a similar kind of expression pattern was observed where levels of both cytokines were higher at $24 \mathrm{hps}$. As activation of pro-inflammatory cytokine cascade against infection is considered as a marker of early immunity, induction of cytokine levels at or after $24 \mathrm{hps}$ in rohu HKLs following poly I:C stimulation suggested the potential inflammatory role played by these cytokines during viral infection in fish.
\end{abstract}

Keywords: Cytokine Genes; Expression Analysis; Labeo rohita Poly I:C.

\section{Introduction}

The fish do have both (humoral and cellular) innate and specific defense mechanisms, but their immune system is poorly understood at the molecular level [1]. The characterization of the fish immune system is essential for understanding host-pathogen interaction, development of preventive and control measures through vaccinations, immunomodulations or production of disease resistant fish. Cytokines are protein molecules, which regulate the nature of immune responses and play key role in growth, differentiation and activation of various immune molecules. They are secreted upon activation of immune cells induced by various pathogens viz., bacterial, parasitic and viral components. The expression of several cytokine genes in fish in response to pathogens exposure is a critical criterion for measuring immune responses in fish to pathogens [2]. Interleukin 6 (IL-6), interleukin 8 (IL-8), interleukin $1 \beta$ (IL$1 \beta$ ) and tumor necrosis factor $\alpha$ (TNF- $\alpha$ ) are pro-inflammatory cytokines which have been proven to be extremely important in fish during inflammatory responses evoked by pathogen [3]. IL-6 is a pleiotropic cytokine, which regulates acute phase reactions, hematopoietic, inflammation and other various immune responses [4]. Expression of IL-6 gene was found to be stimulated by various inducers viz., lipopolysaccharide (LPS), poly I:C and phorbol 12-myristate 13-acetate (PMA) in both fish and mammals [5]. In Japanese flounder, up-regulation in IL-6 transcript level was observed following challenge with Edwardsiella tarda in kidney and spleen which are expected to harbor lymphocyte populations [4]. Induction in IL-6 level was also evident in poly I:C treated kidney tissues of zebrafish during the first hours of injection which indicates its role in antiviral immunity [6]. IL-8, the first known chemokine or called as CXCL8, plays very important role in initiation of acute inflammation by recruiting immune molecules to the site of infection [7]. In fish, increased level of IL-8 was reported following injection with LPS, poly I:C or infection with pathogenic bacteria which suggests the involvement of this cytokine in fish immune response [7]. TNF- $\alpha$ and IL- $1 \beta$, two important pro-inflammatory cytokines also have been reported to play key roles in anti-bacterial, antiparasitic and anti-viral immunity in fish $[4,8,9]$. Despite their vital role in pathogen induced host immune response, studies on these cytokines have not been discussed in one important Indian major carp species, rohu (Labeo rohita). Currently, this fish species represents one of the valuable aquaculture products in India which is highly on demand among consumers due to its delicious taste and high nutritional value [10]. However, disease problem associated with this fish remains a major constraint for its sustainable production. Though, studies on 
expression pattern of immune molecules following different stimuli and downstream pathways are necessary to understand host-pathogen interaction, research on rohu immune system, in particular is limited. Polyinosinicpolycytidylic acid (poly I:C), a double stranded RNA virus analog mimics viral infection and in fish it has been reported to induce pro-inflammatory responses and anti-microbial activity [11]. It has been successfully used in vivo as well as in vitro to study expression pattern of cytokines in response to viral infection in several fish species [12-15]. In this study, we report in vitro expression analysis of pro-inflammatory cytokines IL-6, IL-8, IL-1 $\beta$ and TNF $\alpha$ in head-kidney leucocytes (important immune competent organ of fish) of rohu following stimulation with poly I:C and discuss its possible use in screening of immunostimulants or their use as inflammatory markers in viral immunity studies.

\section{Methods}

\section{Experimental animals}

Rohu (L. rohita) juveniles (average weight $70.0 \pm$ $5.2 \mathrm{~g}$ ) were obtained from the farm of the Central Institute of Freshwater Aquaculture (CIFA), Bhubaneswar, India. Fish were acclimatized in fiber-reinforced plastic tanks of $500 \mathrm{~L}$ capacity for two weeks before conducting the experiment. About onetenth of tank water was exchanged daily and the basic physicochemical water parameters were measured regularly to maintain the optimum water quality. The temperature in water tanks was found to be $25-28{ }^{\circ} \mathrm{C}$ throughout the experimental period. Fish were fed with commercial pellet feed (ACI Godrej Pvt. Ltd., India) at $2.5 \%$ of body weight in two divided doses.

\section{Isolation of head kidney leucocytes (HKLs)}

For isolating HKLs, fish were sacrificed with overdose of anaesthesia (MS222, Sigma-Aldrich Chemicals Co., USA) and dissected. Head-kidney tissues were collected in $1.5 \mathrm{ml}$ tubes containing $1 \mathrm{ml}$ Leibovitz L-15 medium supplemented with $0.1 \%$ gentamycin, $18 \mathrm{mM} \mathrm{NaHCO}_{3}, 25$ mM HEPES, pH 7.4 (SigmaAldrich, USA) and kept in ice. Then the tissues were placed on cell strainer (100 $\mu \mathrm{m}$ dia, BD Bioscience) and meshed with the above medium. The minced tissues were re-suspended in $3 \mathrm{ml}$ medium and layered slowly over 51\% Percoll gradient (SigmaAldrich, USA). Samples were centrifuged at $500 \mathrm{xg}$ for $45 \mathrm{~min}$ at $4{ }^{\circ} \mathrm{C}$. The leucocyte band was carefully pipetted out to another tube containing $2-3 \mathrm{ml}$ of L-15 medium. The supernatant was discarded after centrifuging the cells at $800 \mathrm{x}$ g for $10 \mathrm{~min}$ at $4{ }^{\circ} \mathrm{C}$ and pellet was re-suspended in $1 \mathrm{ml}$ medium and kept on ice. After viability checking and cell counting using Trypan blue (Sigma-Aldrich, USA), $2 \times 10^{7}$ leucocyte cells were seeded into each well of cell culture plate.

\section{Stimulation of HKLs with poly I:C for expression study}

Cells were treated with poly I:C $(50 \mu \mathrm{g} / \mathrm{ml}$, SigmaAldrich, USA) and incubated at $28^{\circ} \mathrm{C}$. Each treatment was carried out in triplicate and un-treated cells served as control. Cells were collected by scrapping thoroughly at $0,1,3,6,12,24$, and 72 and $96 \mathrm{~h}$ post-stimulation (hps) and centrifuged at $11,000 \mathrm{x}$ g at 10 ${ }^{\circ} \mathrm{C}$ for five minutes. Supernatant was discarded and cells were resuspended in $1 \mathrm{ml}$ TRI reagent (Sigma-Aldrich, USA), mixed well through vortex for a minute and stored at $-70{ }^{\circ} \mathrm{C}$ for RNA extraction.

\section{RNA extraction and cDNA synthesis}

RNA extraction was carried out using TRI reagent following manufacturer's instruction and RNA samples were stored at $-70{ }^{\circ} \mathrm{C}$. Before synthesizing cDNA, quality and concentration of RNA samples were checked through NanoDrop ND 1000 (NanoDrop Technologies Inc., USA) by measuring optical density at 260 and $280 \mathrm{~nm}$, and $1 \mu \mathrm{g}$ of RNA was treated with DNase I (Fermentas, Canada) according to manufacturer's instruction. To this reaction mixture $1 \mu \mathrm{l}(1 \mathrm{U} / \mu \mathrm{l})$ of RNase inhibitor (Fermentas, Canada) was added in order to inhibit the RNase activity. All these DNase I-treated RNA samples were further processed for cDNA synthesis using MMLV-RT (Sigma-Aldrich, USA) following manufacturer's instruction. The synthesized cDNA samples were stored at $-20^{\circ} \mathrm{C}$ until further use.

\section{PCR, cloning and cytokine expression analysis}

qPCR was carried out for all the four cytokine genes using pairs of published gene specific (TNF- $\alpha$ ) primers [16] or self designed primers before (using primer premier 5, version 5.0, Premier Biosoft International, Palo Alto, CA) for each gene. Primer pairs for IL-8 and IL-1 $\beta$ were designed from available sequences of L. rohita IL-8 (HM363518.1) and IL-1 (AM932525.1) in NCBI database whereas primers for IL-6 gene were derived from mRNA seq of rohu IL-6 contig 88018[17]. Primer sequences and their optimum annealing temperatures are given in Table 1.

Table 1: Primers used in this study with their annealing temperature and size of amplicon produced

\begin{tabular}{|c|c|c|c|}
\hline \multirow{2}{*}{ Target gene } & Primer sequence (5'-3') & $\begin{array}{c}\text { Annealing } \\
\text { temperature ('C) }\end{array}$ & $\begin{array}{c}\text { Size of PCR } \\
\text { amplicon (bp) }\end{array}$ \\
\hline \multirow{2}{*}{ IL-6 } & F-GGACCGCTTTGAAACTCT & 54.3 & 212 \\
\hline
\end{tabular}




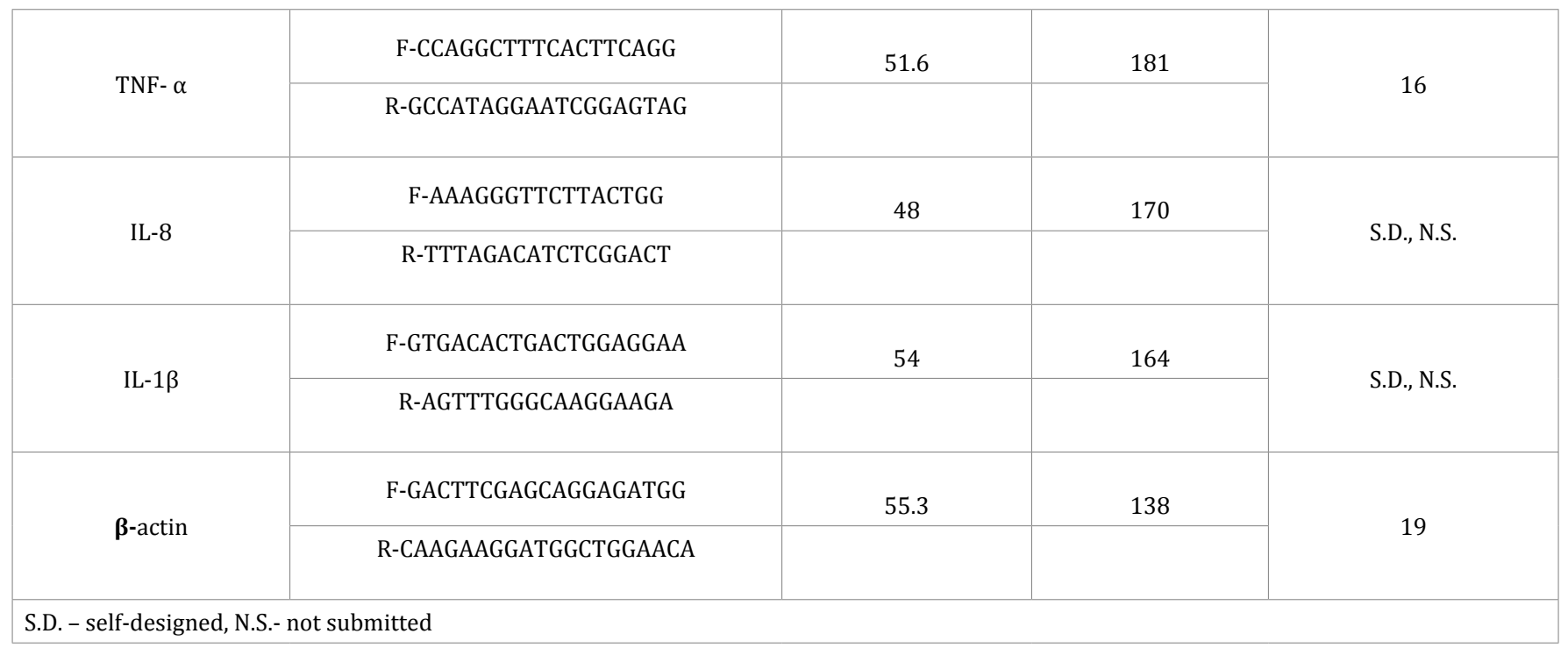

All the amplifications were carried out using $1 \mu \mathrm{l}$ of reversetranscribed cDNA as detailed elsewhere [18]. The generated PCR products were purified by PCR product purification kit (Bangalore Genei, Bangalore) and were cloned into $\mathrm{T}$ cloning vector using an instant cloning kit (Bangalore Genei, Bangalore) according to manufacturer's instructions. Three positive clones were sequenced and bioinformatics analysis was carried out for confirmation of the sequences (data not shown).

PCR reaction was carried out in a Light Cycler 480 (Roche, Germany) using Light Cycler 480 SYBR Green I master reaction mix (Roche, Germany) following the manufacturer's instructions. Briefly, a reaction mixture of $10 \mu \mathrm{l}$ was prepared using $1 \mu \mathrm{l}$ cDNA, $5 \mu \mathrm{l}$ of $2 \times$ Light Cycler SYBR Green I mix, $1 \mu \mathrm{l}$ of each primer, and $2 \mu \mathrm{l}$ of water provided in the kit. The qPCR program consisted of pre-denaturation of $95^{\circ} \mathrm{C}$ for $10 \mathrm{~min}$ and 45 cycles of amplification at $95^{\circ} \mathrm{C}$ for $10 \mathrm{sec}$, annealing temperature (Table 1) for $10 \mathrm{sec}$ and $72{ }^{\circ} \mathrm{C}$ for $10 \mathrm{sec}$. Each sample was taken in duplicate and negative control (sample without cDNA) was run in each plate. Housekeeping gene $\beta$-actin was run as a calibrator [19]. Specificity of qPCR was checked through melt curve analysis at $95^{\circ} \mathrm{C}$ for $10 \mathrm{sec}, 65^{\circ} \mathrm{C}$ for $1 \mathrm{~min}$ and $95^{\circ} \mathrm{C}$ for $1 \mathrm{~min}$.

\section{Data analysis}

Quantification cycle values (CQ) were derived using second derivative maximum method for absolute quantification analysis using Light Cycler 480 software [20]. Calculation of $\mathrm{N}$-fold differential expression was carried out using comparative CQ method [21]. Mean value of untreated samples at $0 \mathrm{~h}$ was taken as calibrator which $\Delta \mathrm{Cq}$ value (average $\mathrm{Cq}$ of sample average Cq of $\beta$-actin) was subtracted from $\Delta \mathrm{Cq}$ of each sample to get $\Delta \Delta \mathrm{Cq}$. Fold expression of each sample relative to calibrator was calculated as $2{ }^{-\Delta \Delta C q}$. The average fold expression of triplicate samples of each time period was presented as mean \pm S.E. Significant difference between different time points was analyzed by one-way ANOVA followed by Duncan's multiple range tests ( $p$ $\leq 0.05$, statistically significant).

\section{Results}

Transcriptional changing of pro-inflammatory cytokines in rohu HKLs following stimulation with poly I:C is presented in Fig. 1.

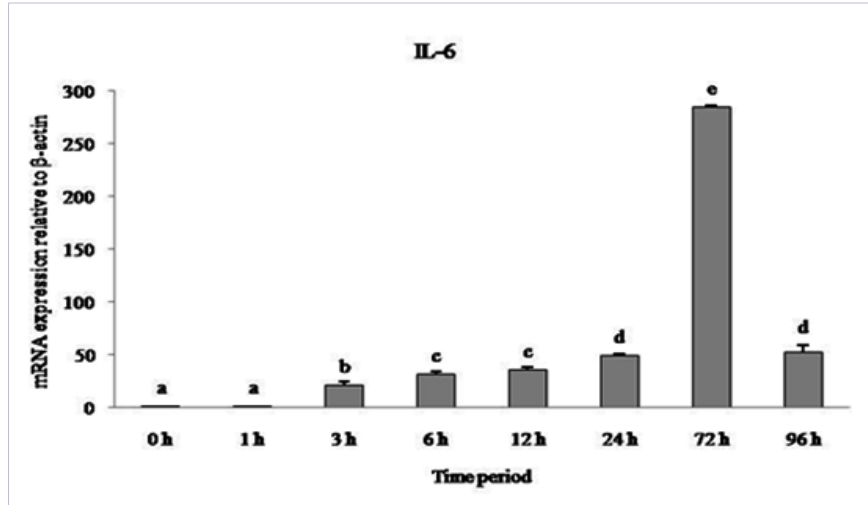

(a)

Figure 1a:

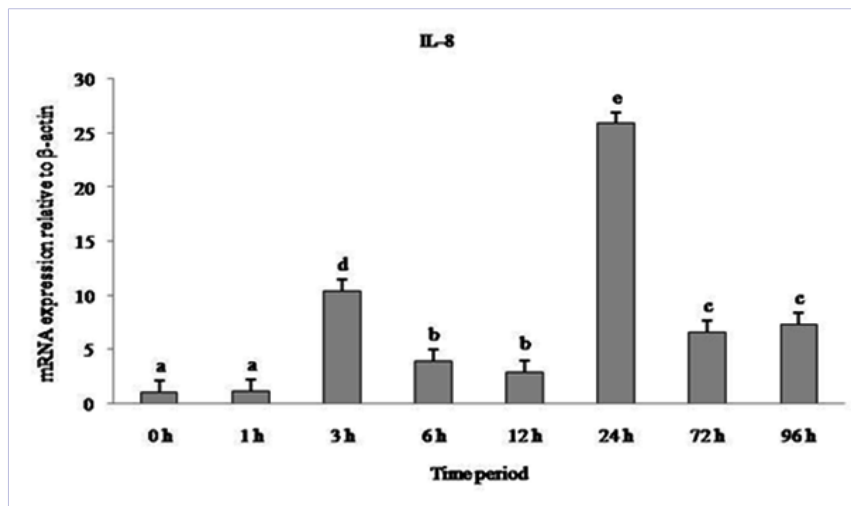

(b)

Figure 1b: 


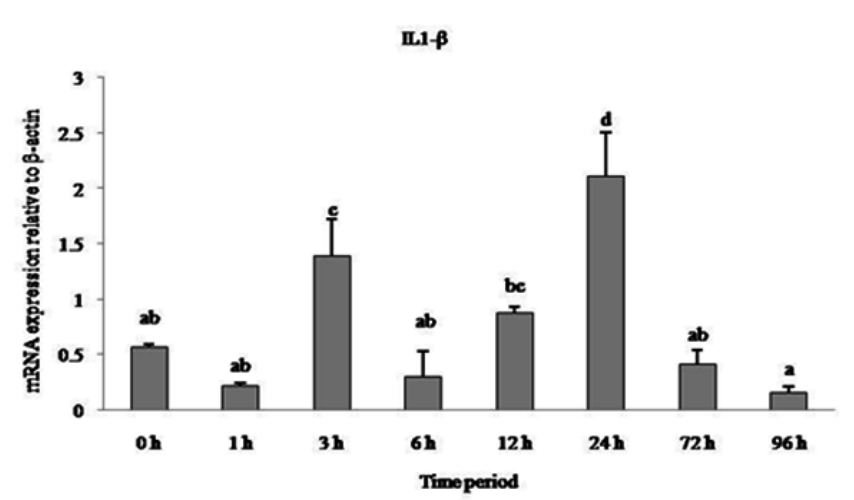

(c)

\section{Figure 1c:}

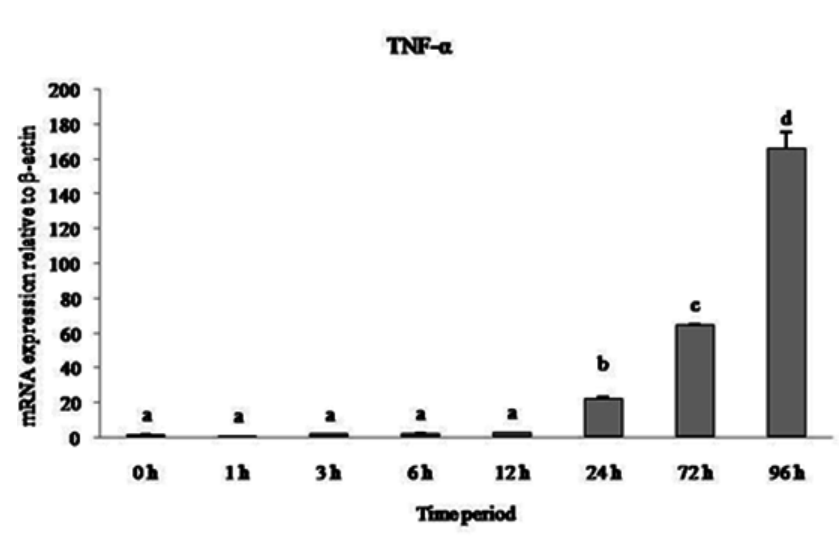

(d)

Figure 1d: Variation in expression pattern of cytokines in head-kidney leucocytes of rohu following induction with poly I: C. The fold difference was calculated as $2-\Delta \Delta \mathrm{Cq}$, where $\Delta \Delta \mathrm{Cq}=(\Delta \mathrm{Cq}$ sample $-\Delta \mathrm{Cq}$ calibrator) and $\Delta \mathrm{Cq}=$ (Cq value of target gene - Cq value of $\beta$-actin). The average $\mathrm{Cq}$ value of the un-induced leucocytes was used as calibrator in the analysis.

Though very negligible level of expression of IL-6 was detected in un-induced HKLs, the transcript level remarkably raised at 3 hps and the same reached its peak at $72 \mathrm{hps}$ (Fig. 1a). A similar pattern of expression was observed in case of IL-8 and IL-1 $\beta$ transcripts where significant up-regulation of both the genes was observed at $24 \mathrm{hps}$ after a transient rise at $3 \mathrm{hps}$ (Fig. 1b and Fig. 1c). Low expression of TNF- $\alpha$ was again seen up to 12 hps including in uninduced HKLs. However, significantly higher expression of this cytokine gene was found at 96 hps (Fig. 1d).

\section{Discussion}

Pro-inflammatory cytokines enable organisms to generate immunity in response to microbial invasion and inflammation [13]. Although primary investigations in rohu have contributed to extend our knowledge on role of various immune molecules during infections, responses related to cytokines remained unsolved in this species. Herein, using poly I:C in vitro, we demonstrated that this viral analog is capable of inducing proinflammatory cytokines in HKLs of rohu which might mimic viral infection or stimulation in true sense in vivo.

In several fish species, expression of IL- 6 has been found to be induced in immune tissues (viz., head-kidney, spleen) by a number of stimuli viz., LPS, peptidoglycan, DNA, poly I:C and IL-1 $\beta$ [22]. In the present study, significant up-regulation of IL-6 in rohu HKLs at 72 hps with poly I:C might be due to the contribution of prior induction of IL-1 $\beta$ (increased at $24 \mathrm{hps}$ as observed here). Induction of IL-6 level by a variety of viruses as well as poly I:C in diploid fibroblasts and in leucocyte cultures in vitro in human and mouse suggests its role in virus induced immunity [5]. In zebrafish kidney tissues injected with poly I:C, elevated level of IL- 6 was maintained up to $6 \mathrm{~h}$ post-injection after which the level returned to the baseline value [6]. However, upregulation of IL-6 level at $72 \mathrm{hps}$ in rohu indicates a late cytokine response to the viral analog. IL- $1 \beta$ was the first cytokine to be identified in fish and both IL- 8 and IL-1 $\beta$ have been reported to be stimulated in response to viral imitator in a number of fish species [14, 23, and 24]. In the present study, induction of both IL$1 \beta$ and IL- 8 in HKLs of rohu at 24 hps with poly I:C might be due to the synergistic relationship shared by these two cytokines. In spleen of large yellow croaker, IL-8 level was found to be elevated at 3-6 hps whereas in head-kidney the level was higher from 1224 hps with poly I:C [7]. Positive stimulatory effect of poly I:C on IL-1 $\beta$ was also described in human dendritic cells and murine macrophage cell lines [25]. IL-8 in fish has been proved to mediate stimulated migration of neutrophils, macrophages, peripheral blood leucocytes and head-kidney leucocytes [26, 27]. Our result suggested that rohu IL-8 might play an important role in headkidney during viral infection by attracting immune cells to the site. An up-regulated TNF- $\beta$ at 96 hps in rohu HKLs indicated a late response of this molecule to the viral imitator in comparison to other cytokines. However, in addition to interferon mediated anti-viral immunity, viral infection also induces expression of TNF and other chemokines [9]. Poly I:C, the synthetic analog of double stranded RNA virus is recognized by toll-like receptor 3 (TLR3) which activates a number of signal transduction pathways and upregulates an array of immune genes [28]. In in silico analysis, rohu TLR3 has been found to possess key binding domains for poly I: $\mathrm{C}$ and dsRNA of fish reovirus [29]. Therefore, it is possible that rohu TLR3 alone or along with other TLR homologues might play a crucial role in recognizing poly I:C and regulating expression level of cytokines. Since IL- 6 together with TNF- $\alpha$ and IL-1 $\beta$ constitutes the group of first cytokines to be produced in host upon exposure to pathogen attack, their expression including that of IL-8 at almost $24 \mathrm{hps}$ or after that indicates a late initiation of cytokine cascade in rohu HKLs upon viral infection.

\section{Conclusion}

Our study shows that in rohu, poly I:C is well capable of inducing anti-viral immunity in HKLs by stimulating expression of pro-inflammatory cytokines. Among the four cytokines 
studied, IL-1 $\beta$ and IL-8 were up-regulated earlier followed by IL- 6 and TNF- $\alpha$. This work also suggests that interferons, the core anti-viral molecules are not the only molecules to be involved in anti-viral immunity. However, studies in vivo will further help to understand the underlying mechanism of the immunity provided by these cytokines following viral infection.

\section{Acknowledgements}

Authors are thankful to the Director, Central Institute of Freshwater Aquaculture, Kausalyaganga, Bhubaneswar, India for providing necessary facilities during this study.

\section{Declarations}

\section{Conflict of interest}

All authors declare that they have no conflicts of interest related to the work presented in this article.

\section{Ethical approval}

All the animal experiments were carried out according to the Institute ethical committee.

\section{References}

1. Tanekhy M, Matsuda S, Itano T, Kawakami H, Kono T, Sakai M Expression of cytokine genes in head kidney and spleen cells of Japanese flounder (Paralichthys olivaceus) infected with Nocardia seriolae. Vet Immunol Immunopathol. 2010;134(3-4):178-183. doi: 10.1016/j.vetimm.2009.09.001

2. Sakai M. Current research status of fish immunostimulants. Aquaculture. 1999;172(1-2):63-92.

3. Covello JM, Bird S, Morrison RN, Battaglene SC, Secombes CJ, Nowak BF. Cloning and expression analysis of three striped trumpeter (Latris lineata) pro-inflammatory cytokines, TNF-a, IL-1b and IL-8, in response to infection by the ectoparasitic, Chondracanthus goldsmidi. Fish Shellfish Immunol. 2009;26:773-786.

4. Nam B, Byon J, Kim Y, Park E, Cho Y, Cheong J. Molecular cloning and characterisation of the flounder (Paralichthy solivaceus) interleukin-6 gene. Fish Shellfish Immunol. 2007;23(1):231-236. doi: 10.1016/j. fsi.2006.10.001

5. Bird S, Zou J, Savan R, Kono T, Sakai M, Woo J, et al. Characterisation and expression analysis of an interleukin 6 homologue in the Japanese pufferfish, Fugu rubripes. Dev Comp Immunol. 2005;29(9):775-789. doi: 10.1016/j.dci.2005.01.002

6. Varela M, Dios S, Novoa B, Figueras A. Characterisation, expression and ontogeny of interleukin- 6 and its receptors in zebrafish (Danio rerio). Dev Comp Immunol. 2012;37(1):97-106. doi: 10.1016/j. dci.2011.11.004

7. Li C, Yao CL. Molecular and expression characterizations of interleukin-8 gene in large yellow croaker (Larimichthys crocea). Fish Shellfish Immunol. 2013;34(3):799-809. doi:10.1016/j. fsi.2012.12.019

8. Mladineo I, BlockBA. Expression of cytokines IL-1 $\beta$ and TNF- $\alpha$ in tissues and cysts surrounding Didymocystis wedli (Digenea, Didymozoidae) in the Pacific bluefin tuna (Thunnus orientalis). Fish Shellfish Immunol. 2010;29(3):487-493. doi:10.1016/j.fsi.2010.05.008

9. Verriera ER, Langevin C, Benmansour A, Boudinot P. Early antiviral response and virus-induced genes in fish. Dev Comp Immunol. 2011;35(12):1204-1214. doi:10.1016/j.dci.2011.03.012

10. FAO. Food and Agriculture Organization of the United Nations: The State of World Fisheries and Aquaculture, (Rome).2013.

11. Fierro-Castro C, Barrioluengo L, López-Fierro P, Razquin BE, Carracedo B, Villena AJ. Fish cell cultures as in vitro models of pro-inflammatory responses elicited by immunostimulants. Fish Shellfish Immunol. 2012;33(2):389-400. doi:10.1016/j.fsi.2012.05.019

12. Harun NO, Costa MM, Secombes CJ, Wang T. Sequencing of a second interleukin-10 gene in rainbow trout Oncorhynchus mykiss and comparative investigation of the expression and modulation of the paralogues in vitro and in vivo. Fish Shellfish Immunol. 2011;31(1):107117. doi:10.1016/j.fsi.2011.04.010

13. Monte MM, Wang T, Holland JW, Zou J, Secombes CJ. Cloning and characterization of rainbow trout interleukin-17A/F2 (IL-17A/F2) and IL-17 Receptor A: Expression during infection and bioactivity of recombinant IL-17A/F2. Infect Immun. 2013;81(1):340-353. doi:10.1128/IAI.00599-12

14. Lu D, Bei J, Feng L, Zhang Y, Liu X, Wang L, et al. Interleukin-1 $1 \beta$ gene in orange-spotted grouper, Epinephelus coioides: Molecular cloning, expression, biological activities and signal transduction. Mol Immunol. 2008;45(4):857-867. doi: 10.1016/j.molimm.2007.08.009

15. Seppola M, Larsen AN, Steiro K, Robertsen B, Jensen I. Characterization and expression analysis of the interleukin genes, IL-1 $\beta$, IL-8 and IL-10 in Atlantic cod (Gadus morhua L.). Mol Immunol. 2008;45(4):887-897. doi: 10.1016/j.molimm.2007.08.003

16. KarB, Mohanty J, Hemaprasanth KP, Sahoo PK. The immune response in rohu, Labeo rohita (Actinopterygii: Cyprinidae) to Argulus siamensis (Branchiura: Argulidae) infection: kinetics of immune gene expression and innate immune response. Aquac. Res. 2013. doi: 10.1111/ are.12279

17. Robinson N, Sahoo PK, Baranski M, Mahapatra KD, Saha JN, Das S, et al. Expressed sequences and polymorphisms in rohu carp (Labeo rohita, Hamilton) revealed by mRNA-seq. Mar Biotechnol (NY). 2012;14(5):620-633. doi: 10.1007/s10126-012-9433-8

18. Dash P, Sahoo PK, Gupta PK, Garg LC, Dixit A. Immune responses and protective efficacy of recombinant outer membrane protein $\mathrm{R}$ (rOmpR)-based vaccine of Aeromonas hydrophila with a modified adjuvant formulation in rohu (Labeo rohita). Fish Shellfish Immunol. 2014;39(2):512-523. doi:10.1016/j.fsi.2014.06.007

19. Sahoo PK, Das S, Mahapatra KD, Saha JN, Baranski M, Ødegård J, et al. Characterization of the ceruloplasmin gene and its potential role as an indirect marker for selection to Aeromonas hydrophila resistance in rohu, Labeo rohita. Fish Shellfish Immunol. 2013;34(5):1325-1334. doi:10.1016/j.fsi.2013.02.020 
20. Ramakers C, Ruijter JM, Deprez RH, Moorman AF. Assumption-free analysis of quantitative real-time polymerase chain reaction (PCR) data. Neurosci Lett. 2003;339(1):62-66.

21. Livak KJ, Schmittgen TD. Analysis of relative gene expression data using real time quantitative PCR and the 2(-Delta Delta C(T)) method. Methods. 2001;25(4):402-408. doi:10.1006/meth.2001.1262

22. Castellana B, Marín-Juez R, Planas JV. Transcriptional regulation of the gilthead seabream (Sparus aurata) interleukin-6 gene promoter. Fish Shellfish Immunol. 2013;35(1):71-78.

23. Laing KJ, Secombes CJ, Chemokines. Dev Comp Immunol 2004;28(5):443-460.

24. Purcell MK, Kurath G, Garver KA, Herwig RP. Winton JR. Quantitative expression profiling of immune response genes in rainbow trout following infectious haematopoietic necrosis virus (IHNV) infection or DNA vaccination. Fish Shellfish Immunol. 2004;17(5):447-462. doi:10.1016/j.fsi.2004.04.017

25. Paulnock DM, Demick KP, Coller SP. Analysis of interferon gammadependent and -independent pathways of macrophage activation. J LEUKOC BIOL. 2000;67:677-682.
26. Sun JS, Zhao L, Sun L. Interleukin-8 of Cynoglossus semilaevis is a chemoattractant with immunoregulatory property. Fish Shellfish Immunol. 2011;30(6):1362-1367

27. Harun NO, Zou J, Zhang YA, Nie P, Secombes CJ. The biological effects of rainbow trout (Oncorhynchus mykiss) recombinant interleukin-8. Dev Comp Immunol. 2008;32(6):673-681. doi: 10.1016/j.dci.2007.10.005

28. GreenTJ, Montagnani C. Poly I:C induces a protective antiviral immune response in the Pacific oyster (Crassostrea gigas) against subsequent challenge with Ostreid herpesvirus (OsHV-1 $\mu$ var). Fish Shellfish Immunol. 2013;35(2):382-388. doi:10.1016/j.fsi.2013.04.051

29. Sahoo BR, Basu M, Swain B, Maharana J, Dixit MR, Jayasankar P, et al. Structural insights of rohu TLR3, its binding site analysis with fish reovirus dsRNA, poly I:C and zebrafish TRIF. Int J Biol Macromol. 2012;51(4):531-543. doi: 10.1016/j.ijbiomac.2012.06.005 